\title{
The Research and Design of Seat based on Ergonomics
}

\author{
Huike $\mathrm{Li}^{\mathrm{a}}$, Fei Li ${ }^{\mathrm{b}}$ \\ School of Mechanical \& Electrical Engineering, Jiangsu Normal University, Xuzhou 221116, China \\ a35766289@qq.com, b56439611@qq.com
}

Keywords: Human-computer interaction; Seat design; Ergonomics.

\begin{abstract}
The seat design is based on the functional conversion of the characteristics of people's working as well as the requirement of leisure, which can present a new human-computer interaction in a novel structure form. In this paper, by analyzing the physiological characteristics of human body's posture, with the general principle of seat design, it discusses the idea of seat design based on ergonomics.
\end{abstract}

\section{Introduction}

Ergonomics takes human physiology, psychological characteristics as the basis, so as to improve the people's working, as well as the quality of life, by using the system engineering and the viewpoint and researching method of information processing psychology, making research on the mutual interaction between human and machine, human and environment, as well as machine and environment, in the field of production, so as to ensure the optimization of the overall performance of man-machine system, which can provide a theoretical basis and method for the "human-machine - environment" system to design a simple operation and labor saving, accurate and safe, efficient and comfortable system.

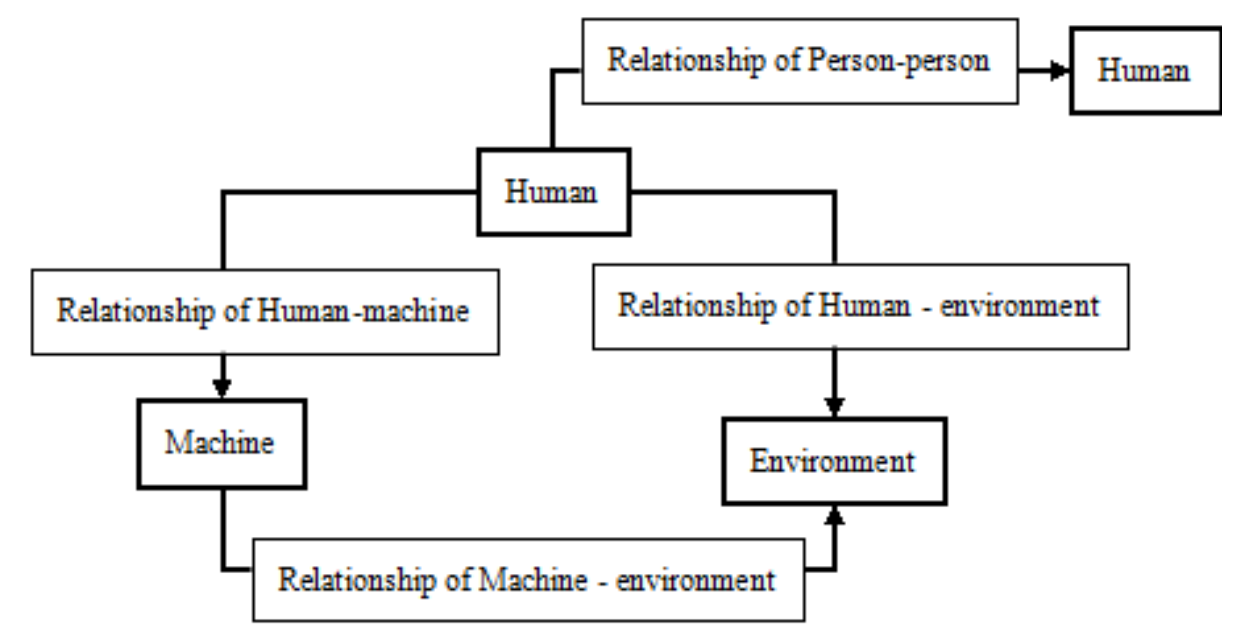

Fig. 1 The relationship of human -machine- environment system

With the development of social production, people must pay attention to ensuring the product with a certain material function, at the same time, who also must pay more and more attention to the comfortableness in the process of using the product. Introducing the principle of ergonomics into the modern seat, its purpose is to optimize the interface between user and product, striving to make the human- machine -environment system achieve the best combination, so as to play its best role.

\section{Analysis of the Physiological Characteristics of Human Body's Posture}

Generally speaking, with normal posture, the spinal lumbar is lordosis, while the sacrum is concave. With a good posture, the pressure can be distributed properly on each disc, muscle tissue can be distributed with static load uniform. The most comfortable posture is that the hips slightly keep away 
from the backrest forward, making the upper body slightly tilted back and keep the body leg angled between $90^{\circ}--115^{\circ}$, at the same time, the angle between the thigh and the lower leg is generally between $100^{\circ}--120^{\circ}$, the angle between leg and sole is generally between $85^{\circ}--95^{\circ}$, while the angle between the big arm and the small arm is generally between $80^{\circ}--90^{\circ}$. If people can remain in this state, the body will reach more comfortable sitting position.

\section{The Main Statistical Function of Human Measurement}

Measurement values that are obtained in the measurement of human are discrete random variables, which may make statistical analysis based on the theory of probability and statistics for the measured data, so as to obtain the statistical regularity and characteristic parameters of the needed group size.

\section{The Mean Value}

As for the measurement value with $n$ samples: $\mathrm{x}_{1}, \mathrm{x}_{2} \ldots \mathrm{x}_{\mathrm{n}}$, the mean value is:

$$
\bar{X}=\frac{X_{1}+X_{2}+\cdots+X_{n}}{n}=\frac{1}{n} \sum_{i=1}^{n} X_{i}
$$

\section{Variance}

The variance shows that the measured value of sample is variable, which is in the direction of the mean value and fluctuated in a certain range. As for the measurement value with $n$ samples the mean value is: $x_{1}, x_{2} \ldots x_{n}$, while the variance of $S_{2}$ can be defined as:

$$
S^{2}=\frac{1}{n-1}\left[\left(X_{1}-\bar{X}\right)^{2}+\left(X_{2}-\bar{X}\right)^{2}+\left(X_{n}-\bar{X}\right)^{2}\right]=\frac{1}{n-1} \sum_{i=1}^{n}\left(X_{i}-\bar{X}\right)^{2}
$$

The square root of the variance $S_{D}$ is known as the standard deviation. As for mean value with $n$ samples: $x_{1}, x_{2}, \ldots, x_{n}$, the general calculation formula of its standard deviation is:

$$
S_{D}=\left[\frac{1}{n-1}\left(\sum_{i=1}^{n} X_{i}^{2}-n \bar{X}^{2}\right)\right]^{\frac{1}{2}}
$$

Sampling error is also called standard error, namely, the standard error of all the samples' mean values. When the standard deviation of the sample data column is $S_{D}$, the volume of sample is $n$, then the calculation formula for the sampling error is:

$$
S_{\bar{X}}=\frac{S_{D}}{\sqrt{n}}
$$

\section{Solve the Body Size at Certain Percentile}

When we know the mean value of human body's measurement size is $\bar{x}$, the standard deviation is $\mathrm{S}_{\mathrm{D}}$, we need to solve the body measurement size $\mathrm{x}$ any percentile, which can be calculated by using the following equation:

Table 1 The main body height size of adults when they are sitting

\begin{tabular}{c|cccccc|cccccccc}
\hline \multicolumn{4}{c|}{ Male (18-60 years old) } & \multicolumn{6}{c}{ Female (18-55 years old) } \\
\hline $\begin{array}{c}\text { Percentile } \\
\text { Sitting } \\
\text { knee high }\end{array}$ & 1 & 5 & 10 & 50 & 90 & 95 & 99 & 1 & 5 & 10 & 50 & 90 & 95 & 99 \\
$\begin{array}{c}\text { Lower leg plus } \\
\text { foot high }\end{array}$ & 340 & 455 & 463 & 492 & 522 & 531 & 548 & 409 & 423 & 430 & 457 & 484 & 492 & 506 \\
\hline
\end{tabular}




\section{The Application of Ergonomics in Seat Design}

The General Principle of Seat Design. The ideal seat, which can distribute the user's body mass reasonably and make the upper arm without bearing the burden of the body mass, while the muscle can have relaxation. Generally speaking, during the period of designing, it should be based on the need of ergonomics and consider the following principles:

(1) The seat form, scale is related with its usage;

(2) It should be based on the accurate data measurement of human body to design;

(3) The gluteal sciatic nodules should bear the main body mass, during the period of the rest, back should also bear part of the body mass;

(4) It should reduce the pressure from the thigh on the seat surface;

(5) It needs to design the backrest, lumbar support and armrest;

(6) It can transform posture freely.

The Conception of Modern Seat Design Based on Ergonomics. During the period of designing the seat, it is usually combined with the seated human body size of ergonomics, so as to design seat from the following four aspects:

Seat Height. Seat height refers to the vertical distance between the surface of seat and ground, the seat height should make the thigh approximately horizontal and make the calf vertical naturally, while feet can lie on the floor. Since seat height in ergonomics is often tilted backwards, thus, the height of the front seat is usually taken as the seat height. Generally, seat height would be properly kept in 380- $450 \mathrm{~mm}$.

Seat Surface Depth. The seat surface depth has also great influence on the comfortableness of body posture, its size should satisfy three conditions: it allows hips to get full support; the lumbar can get support from backrest; there should be a proper distance between the front of seat and the calf. Therefore, during the period of designing the seat, seat surface depth should be moderate, for example, if seat surface depth is too deep, which is more than the length of the thigh, it will have large inclination when people is touched with the backrest, while the lumbar is lack of support point and will exacerbate the degree of muscle's activity and cause fatigue. Usually the seat surface depth should be within 350- $430 \mathrm{~mm}$, which is appropriate.

Seat Surface Width. The width of seat surface is according to the sitting posture and movements of people, which often in the shape with wide front and narrow back. The width of front seat is called front seat width, while the width of the back is called back seat width. The width of the seat should make hips get all the support and have appropriate room for activities, which can be facilitated for the transformation of body posture. Generally, $400-450 \mathrm{~mm}$, as for seat with the arm, it also has to consider the arms of people hold on to the handrail, taking the inner width as the size of the seat surface width, adding appropriate room according to the average width size of people's shoulders, which is generally not less than $500 \mathrm{~mm}$.

Design of inclination angle should include two parts, namely, the inclination angle of seat surface and the inclination angle of the backrest. The inclination angle of seat surface refers to the angle between the seat surface and the horizontal plane. The seat surface should be tilted slightly backward to avoid hips sliding forwards during a long time of sitting, which should be convenient for the back to lean backwards naturally under the influence of gravity, affixed to the backrest to get back support. As for working seat, $5^{\circ}$ is desirable, while $14^{\circ}-24^{\circ}$ is appropriate for rest seat. While the angle of backrest refers to the angle between the backrest and the seat surface of the seat with backrest. From the perspective of keeping the spine in a normal natural form, increasing the comfortableness, the most suitable angle is $95^{\circ}-115^{\circ}$.

The Width and Height of Backrest. The width and height of backrest is related with the width of shoulder and height of shoulder, as for working seat, the height and width of the backrest should take the no interference with the operation of arms as the premise. It can adopt middle or low back, the width is desirable between $320-360 \mathrm{~mm}$; as for the rest seat, it should adopt seat with high backrest and the height of backrest width should be $350-480 \mathrm{~mm}$. 
The Height of Handrails. The main function of handrails is to support the weight of arms, so as to reduce the burden on the shoulders and increase comfortableness. During the change of posture between sitting, standing up or changing sitting posture, arms can use the handrails to support body. In the swing or bumpy state, the handrails can help body to maintain balance and stability. According to the scale of body, the vertical distance between handrails on the surface to the base surface should be $200-230 \mathrm{~mm}$, at the same time, the front of the handrails can slightly elevated, with the change of the inclination angle of seat surface and basic tilting change of backrest, the inclination degree of armrests is $\pm 10^{\circ}$ generally, while the angle of backrest in the horizontal direction is about $\pm 10^{\circ}$, which is generally fits with the shape of seat surface.

\section{Conclusion}

There are many factors that can have influence on the seat design, therefore, designers should consider them according to different situations, such as the geographical impact, influence from the material of seat surface, people's psychological factors and so on. Through designing and evaluating seat scientifically, it can reduce the occurrence of seat occupational diseases effectively, which can increase the comfortableness and efficiency for the people.

\section{References}

[1]KHE Kroemer, HB Kroemer, KE Kroemer-Elbert. 2001, Ergonomics.How to Design for Ease and Efficiency, vol. 39, p. 33-52.

[2]Seokhee Na, Sunghyun Lim, Hwa-Soon Choi. et al.. 2005, Evaluation of driver's discomfort and postural change using dynamic body pressure distribution. International Journal of Industrial Ergonomics, vol. 67, p. 78-90.

[3]Eran Linder-Ganza, Noga Shabshinb,Yacov Itzchakb. et al.. 2006, Assessment of mechanical conditions in sub-dermal tissues during sitting.A combined experimental-MRI and finite element approach, Journal of Biomechanics, vol. 59, p. 49-68.

[4]X.Wu, Rakheja, P.E. 1998, Boileau. Disteibution of human seat interface pressure on a soft automotive seat under vertical vibration. International Journal of Industrial Ergonomics, vol. 26, p. 26-51. 